\title{
Desempenho de um aquecedor solar de água em Manaus
}

\author{
John Harry Harwood (*) \\ Ronaldo de Almeida $\left({ }^{*}\right)$
}

\begin{abstract}
Resumo
Um aquecedor solar de água comercial para fins domésticos foi testado em Manaus tanto no verāo quan. to no inverno. O desempenho foi medido em funçâo da radiação incidente, observando-se a temperatura da àgua no reservatório e na entrada e na saída do coletor. A velocidade de termossifonagem foi medida através de uma injeção de tinta em tubulação transparente. A eficiência variou durante o dia. 0 valor máximo observado foi de $58 \%$ e valores de $37 \%$ são mostrados nos dados analisados em detalhe. O ângulo de inclinaçăo (de 4 até $25^{\circ}$ ) nâo teve influência significativa no desempenho dos coletores. Agua quente (150 I) acima de $45^{\circ} \mathrm{C}$ seria obtida em pelo menos $93 \%$ dos dias do ano.
\end{abstract}

\section{INTRODUÇÃo}

A radiação solar na Amazônia é da ordem de 2000 horas de brilho solar por ano (Schwerdtfeger, 1976). A regiâo então, apesar de nāo ser a mais ensolarada do país, apresenta condiçōes favoráveis de utilização da energia solar.

Correa (1980) mostrou que a demanda de energia para aquecimento de água só para banhos em Manaus é da ordem de $2.233 \mathrm{t}$ de óieo por ano. No momento em que as reservas mundiais de petróleo estão se esgotando é de grande importância tentar substituir este gasto de óleo por aparelhos solares. As experiências descritas neste trabalho foram feitas com esta finalidade.

\section{MATERIAL E MÉtodos}

\section{Aquecedor :}

O aparelho (Fig. 1) possui dois coletores planos de $1,5 \mathrm{~m}^{2}$ cada, ligados a um reservatório de água termicamente isolado com capacidade de 150 litros. Este reservatório pos- sui uma válvula com bóia que o mantém sempre cheio de água da rede. A água da parte inferior do tanque é conduzida até aos painéis onde se aquece e por diferença de densidade (termossifão) volta ao reservatório. A água quente para consumo é fornecida pela saída indicada.

O ângulo dos coletores em relação à horizontal podia ser modificado por meio de parafusos adaptados ao suporte original.

\section{Medidas :}

A velocidade de circulação da água (vazão) nos coletores foi medida injetando-se tinta nanquim através de uma borracha fixada na parede do cano de alimentação dos painéis e obser. vando-se $o$ instante em que a tinta surgisse num outro ponto distante $255 \mathrm{~cm}$ do primeiro. A visão neste ponto era possivel face à exis. tência de um pequeno segmento de tubo plástico no local.

Por meio de termômetros de mercúrio inseridos nos pontos desejados, foram medidas as temperaturas da água ao entrar $\left(T_{1}\right)$ e ao sair $\left(T_{2}\right)$ dos painéis, como também a da uti. lizada para consumo $\left(T_{3}\right)$.

$A$ radiação solar incidente foi medida, usando-se um pirheliômetro Eppley ligado a um po. tenciômetro Leeds \& Northrup.

$\mathrm{Em}$ intervalos regulares durante o dia, normalmente de hora em hora, foram tomadas todas as medições descritas acima.

\section{CÁlculos}

A eficiência dos coletores sob condiçōes de céu limpo foi calculada segundo a equaçăo:

$$
\eta=\frac{\operatorname{Cp} . V\left(T_{2}-T_{1}\right) \times 100 \%}{\text { Ic. } S} \ldots \ldots \ldots
$$

[*] - Instituto Nacional de Pesquisas da Amazônia, Manaus. 


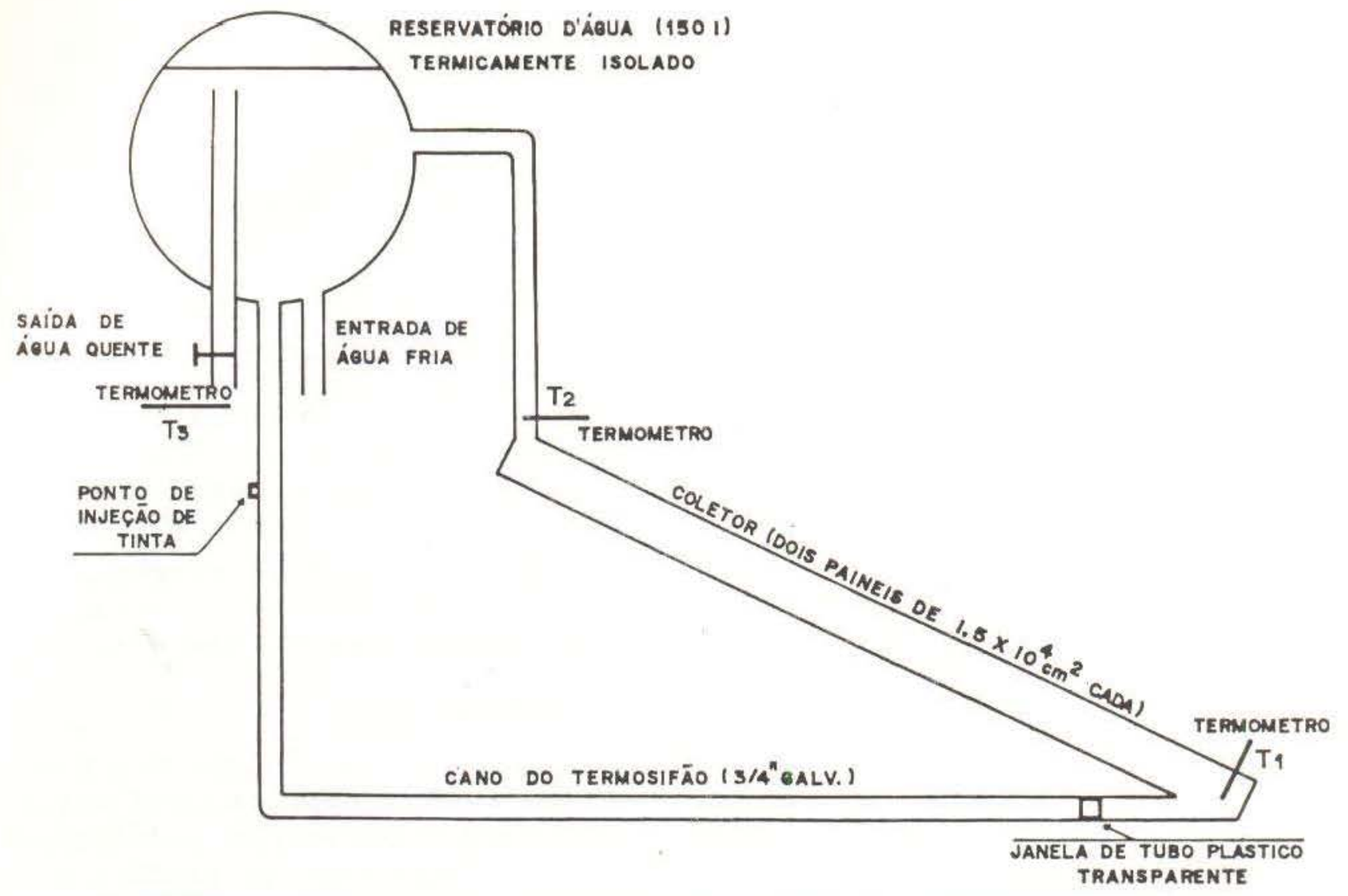

Fig. 1 - Esboço do aquecedor solar de água.

Onde: V é a velocidade dó termossifão, medido em g.min..$^{-1}$

$\mathrm{T}_{2}$ é a temperatura da água, à saída do coletor medido em 9 C.

$T_{1}$ é a temperatura da água à entrada do coletor medido em ${ }^{\circ} \mathrm{C}$. Ic é a valor da radiação incidente no plano do coletor medido em cal. $\mathrm{cm}^{-2} \cdot \mathrm{min}^{-1}$.

Cp. é o calor específico de água, isto é, $1,0 \mathrm{cal} \cdot \mathrm{g}^{-1} \cdot{ }^{9} \mathrm{C}^{-1}$

$\mathrm{S}$ é a superficie total dos coletores, isto é, $3 \times 10^{4} \mathrm{~cm}^{2}$

Esta equação só se aplica em condições estáveis, isto é, em dias limpos porque em condições que variam rapidamente, como ocorre quando uma nuvem passa em frente do sol, Ic varia muito mais rapidamente do que $T_{1}$ e $T_{2}$, destruindo assim o equilíbrio representado pela equação.

Em condições de céu aberto pode-se aplicar a equação :

$$
\eta=\frac{\mathrm{Cp} \cdot \mathrm{M} \cdot \Delta \mathrm{T}_{3} \times 100}{\operatorname{sic} \times \mathrm{S}}
$$

onde: $M$ é a massa de água no reserva. tóriơ, isto é, $150 \times 10^{3} \mathrm{~g}$.

$\Delta \mathrm{T}_{3}$ (medido em ọ $\mathrm{C}$ ) é o aumento de temperatura da água dentro do reservatório durante o dia;

Slc (medido em cal. $\mathrm{cm}^{-2}$ ) é o integral do fluxo da radiação recebida no plano dos coletores até a água no reservatório chegar ao seu valor máximo;

$S$ é a área total dos coletores $\left(3 \times 10^{4} \mathrm{~cm}^{2}\right)$.

Cp é o calor específico de água, isto é, $1,0 \mathrm{cal} \cdot \mathrm{g}^{-1}$. ${ }^{\circ} \mathrm{C}^{-1}$

Deve ser lembrado que a eficiência calculada usando a equação 2 é a do conjunto total (coletor, tubulação e tanque) enquanto a eficiência calculada usando a equação 1 é estritamente a dos coletores. 


\section{RESULTADOS}

Comportamento do aquecedor em um dia limpo

A Fig. 2 apresenta o desempenho do aquecedor inclinado de $25^{\circ}$ para o norte em um dia ensolarado, (06.07.79). A curva da radiação é quase perfeitamente simétrica com o máximo de $1,3 \mathrm{cal} . \mathrm{cm}^{-2} \cdot \mathrm{min}^{-1}$ obtido às 12 horas.

A temperatura máxima da água atingida na saida do coletor foi de $77^{\circ} \mathrm{C}$ às $14 \mathrm{hs}$, enquanto que no tanque foi de $76^{\circ} \mathrm{C}$ às $15 \mathrm{hs}$. Todas as temperaturas diminuem após às $15 \mathrm{hs}$, sendo que o tanque, com melhores condições de isolamento por unidade de massa, resfria mais lentamente.

A velocidade da termossifonagem aumentou rapidamente no início do período, mantendo-se depois quase constante, até o ponto em que a temperatura da saida do coletor começa a diminuir.

A eficiência chega a um máximo no início do dia, visto que as perdas de calor do coletor são menores quando este está mais frio, isto é, antes da água aquecer muito. O valor máximo de eficiência observado na Fig. 2 é de $37 \%$, calculado segundo a equação 1 acima.
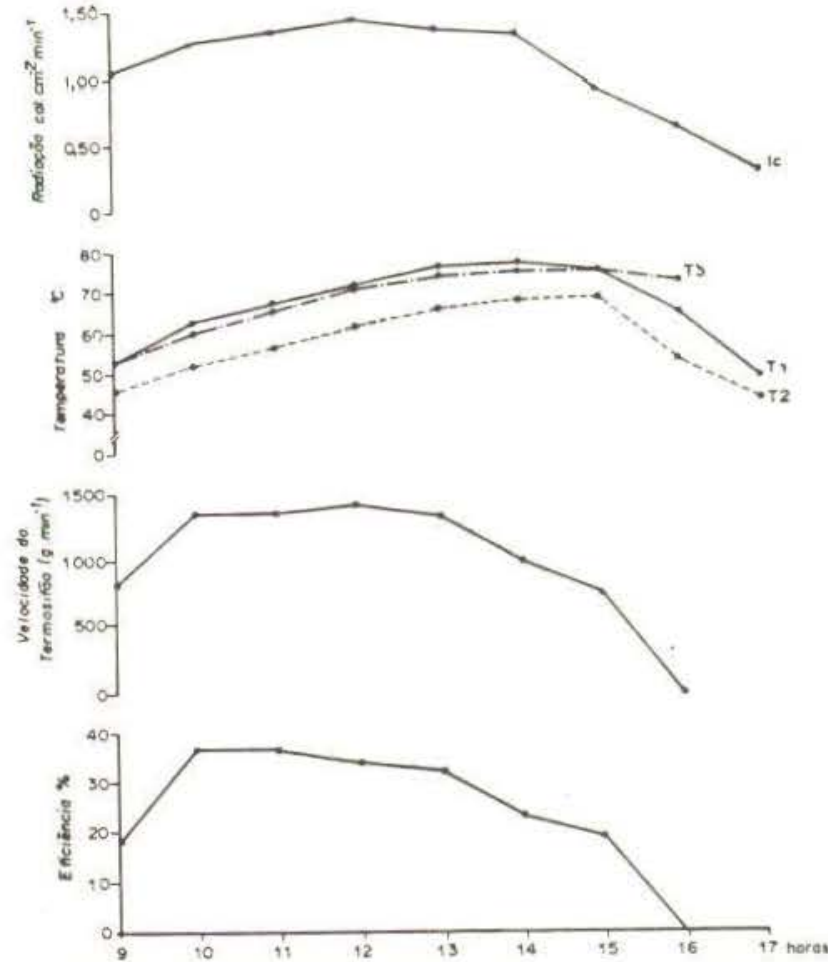

Fig. 2 - Dsempenho do aquecedor solar de água num dia timpo $(6 / 7 / 79)$. A: Variação da densidade de fluxo de radiaçāo (Ic) recebida no coletor. B: Variaçăo da temperatura da água no reservatório $\left(\mathrm{T}_{3}\right)$ e na entrada $\left(T_{1}\right)$ e na saida $\left(T_{2}\right)$ do coletor. $C$ : Velocidade do termossifão. D: Variaçấo da eficiência calculada segundo a equaçāo (1) do texto. Ángulo do coletor com o horizontal $-25^{\circ}$ olhando para o Norte.

TABELA 1 - Desempenho de um aquecedor solar de água num dia nublado $(09 / 06 / 80)$

\begin{tabular}{|c|c|c|c|c|c|}
\hline Horas & $\begin{array}{c}\mathrm{T}_{3} \\
\text { Temperatura da água } \\
\text { no reservatório } \\
\left({ }^{\circ} \mathrm{C}\right)\end{array}$ & $\begin{array}{l}\text { Ic } \\
\text { Radiaçăo solar no } \\
\text { plano do coletor } \\
\text { (cal. } \mathrm{cm}^{-2}, \min ^{1} \text { ) }\end{array}$ & $\begin{array}{l}\text { Ic } \\
\text { Integral da radiaçâo } \\
\text { solar até a água che- } \\
\text { gar à sua tempera- } \\
\text { tura máxima } \\
\text { (cal.cm }{ }^{2} \text { ) }\end{array}$ & $\begin{array}{c}\Delta T_{3} \\
\text { Aumento máximo } \\
\text { da temperatura } \\
\text { da água } \\
\left({ }^{\circ} \mathrm{C}\right)\end{array}$ & $\begin{array}{c}\text { ॠ } \\
\text { Eficiência calcula- } \\
\text { da segundo a } \\
\text { equaçâo } 2 \\
\text { (veja texto) } \\
(\%)\end{array}$ \\
\hline 8.30 & 35,0 & 0 & & & \\
\hline 9.40 & 34,5 & 0,137 & & & \\
\hline 11.00 & 35,0 & 0.387 & & & \\
\hline 12.00 & 38,5 & 0,666 & & & \\
\hline 13.00 & 42,0 & 0,854 & & & \\
\hline 14.00 & $45,0^{\circ}$ & 0,590 & $136^{\cdots}$ & 10 & 37 \\
\hline 15.00 & 45,0 & 0,457 & & & \\
\hline 16.00 & 45,0 & 0,316 & & & \\
\hline 17.00 & 45,0 & 0,077 & & & \\
\hline
\end{tabular}

Desempenho... 
Comportamento do aquecedor em um dia nublado

A Tab. 1 mostra o comportamento do aquecedor solar num dia bem nublado (09.06.80). A temperatura da água dentro do reservatório atingiu o seu máximo às 14 horas. A eficiência do aquecedor até este momento era de $37 \%$ calcuiado segundo a equação 2 acima.

\section{Efeito do Ângulo de Inclinação dos Coletores}

A Tab. 2 mostra as temperaturas máximas observadas dentro do reservatório de água durante 3 dias de operação em cada ângulo com o céu predominantemente limpo. A velocidade máxima do termossifão está também mostrada. Verifica-se que o ângulo de inclinação teve pouca influência no desempenho do aquecedor.

TABELA 2 - Temperatura máxima da água no reserva. tório e velocidade máxima do termossifăo em função do ângulo de inclinaçăo dos coletores

\begin{tabular}{ccc}
\hline $\begin{array}{c}\text { Angulo } \\
\text { dos } \\
\text { Coletores }\end{array}$ & $\begin{array}{c}\text { Temperatura máxima } \\
\text { da água }\left({ }^{\circ} \mathrm{C}\right)\end{array}$ & $\begin{array}{c}\text { Velocidade máxima } \\
\text { do termossifāo } \\
\text { g.min -1 }\end{array}$ \\
\hline $25^{\circ}$ & 77 & 1615 \\
$19^{\circ}$ & 74 & 1454 \\
$14^{\circ}$ & 76,5 & 1557 \\
$4^{\circ}$ & 75 & 1615 \\
\hline
\end{tabular}

\section{Disponibilidade de água quente}

A. Fig. 3 mostra a disponibilidade de água quente às 17 horas em um chuveiro alimentado por um aquecedor do tipo estudado, instalado na residência do Governador do Estado do Amazonas.

Água quente acima de $60^{\circ} \mathrm{C}$ foi obtida durante 37 minutos de uso do chuveiro (vazão de $3,461 . \mathrm{min}^{-1} \mathrm{~J}$, e acima de $45^{\circ} \mathrm{C}$ durante 43 minutos. O dia năo estava perfeitamente limpo, tendo chovido ao meio-dia. A quantidade de eletricidade que teria sido necessária para aquecer a mesma massa de água acima de $45^{\circ} \mathrm{C}$ seria de $4,76 \mathrm{kWh}$.

\section{DISCUSSÃo}

O aquecimento solar da água é uma tecnologia estabelecida, porém sua economicidade depende de vários fatores: insolação do local, custo dos coletores, eficiência dos coletores e custo comparativo com outras fontes de energia.

A temperatura da água quente para banhos deve estar acima de $45^{\circ} \mathrm{C}$. Esta temperatura foi atingida em todas as experiências feitas. mesmo com um nivel de radiação globa! 202 cal. $\mathrm{cm}^{-2}$ por dia. Villa Nova et al. (1978) mostraram que de 340 dias observados, de maio 1976 até maio de 1977, somente 25 dias tinham valores de radiação global inferior a este valor. Assumindo que o ano estudado por estes pesquisadores seja típico, pode-se concluir que o aquecedor fornecerá água adequada para banhos em $93 \%$ dos dias do ano.

Segundo os resultados, o ângulo de inclina. ção dos coletores não influencia significativamente o desempenho do aquecedor, contudo uma leve inclinação ajuda a manter os vidros dos coletores limpos. Villa Nova et al. (1978) mostraram que a radiação por dia é maiơr durante o período abril-setembro (quando em $\mathrm{Ma}$. naus o sol está no norte) do que no período outubro-maio (quando o sol em Manaus está no sul) conseqüentemente julga-se melhor orientar o coletor para o sul de maneira a aumentar a eficiência da coleção durante o período de menor insolação. Assim, por exemplo, outros coletores instalados pelo INPA têm uma orientação de $7^{\circ}$ inclinados para o Sul.

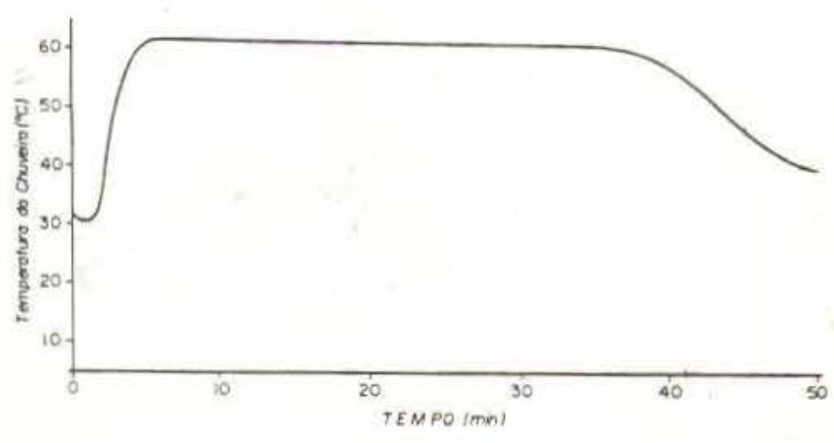

Fig. 3 - Disponibilidade de água quente num chuveiro ligado a um aquecedor solar de água (Vazão $3.46 \mathrm{I} / \mathrm{min}$, experiência feita às $17: 00$ hs no dia $10 / 4 / 80$ - um dia ensolarado com um pouco de chuva ao meio-dia). 
Qualquer manual de energia solar, por exemplo Palz (1978), mostra que a eficiência de um coletor cai à medida que a sua temperatura aumenta. A maior eficiência observada em todos os testes desta série era de $58 \%$ com os coletores quase frios entre 9 e 10 horas da manhã. A eficiência média era de $37 \%$ como descrita acima até a temperatura da água chegar ao seu máximo. A partir deste momento a eficiência do sistema é 0 . Assim sendo. a radiação da tarde a partir das $14: 00$ hs. não influi nas experiências descritas na Fig. 2 e na tabela 1. Para aproveitar esta radiaçāo existem duas possibilidades: (1) tirar a água quente ao meio dia, de maneira que os coletores trabalhem com um tanque frio ao começo da tarde ou (2) aumentar o tamanho do reservatório de maneira que a água não chegue muito quente tão cedo. A tática (1) seria mais apropriada para cantinas que usam água para lava louça ao meio-dia e à noite. A segunda estratégia é mais apropriada para fins domésticos onde a maioria da familia vai tomar banho à noite. Conseqüentemente se aconselha aumentar o tamanho do reservatório deste aparelho para usos domésticos.

De qualquer maneira o aparelho já se mostra adequado a fornecer $150 \mathrm{I}$ de água quente acima de $45^{\circ} \mathrm{C}$ em $93 \%$ dos dias do ano, dando a esperança que $93 \%$ das 2233 toneladas de óleo usadas por ano para aquecimento de água para banhos em Manaus (Correa, 1980) podem ser substituídas, representando uma economia anua! de 2.076 toneladas de óleo.

\section{SUMMARY}

A commercial, domestic solar water heater was tested in Manaus during the whole year round. The performance was monitored using various parameters: incident solar radiation, temperature of water in the tank and at the entrance and exit of the collectors, as well as the velocity of the thermosiphon. The latter was measured by injecting printing ink into the pipework which was fitted with transparent plastic windows in appropriate places.

The efficiency of the collectors was seen to vary during the day. The maximum value ever observed was $58 \%$ and values of $37 \%$ are calculated for the data described in detail. Collector angle in the range $4^{\circ}-25^{\circ}$ did not affect performance significantly. Hot water for showers $(150 \mathrm{I})$ at $>45^{\circ} \mathrm{C}$ should be obtained in $93 \%$ of the days of the year.

\section{REFERENCIAS BIBLIOGRAFICAS}

CORREA, Cleusa Maria

1980 - Estimativa do consumo de combustivel gasto com aquecimento de água em Manaus. Acta Amazonica, 10 (4): 930-33.

PALZ, Wolfgang

1978 - Solar Eletricity. Butterworth, London, 292pp. SCHWERDTFEGER, WERNER

1976 - Climates of Central and South America. World Survey of Climatology V. 12. Elsevier Scientific, Amsterdam, 532pp.

VILLA NOVA, N.A.; GOES RIBEIRO, M.N.; NOBRE, C.A.; SALATI, E.

1978 - Radiaçāo Solar em Manaus. Acta Amazônica, 8 (3): $417-421$.

(Aceito para publicaçẩo em 22/04/81) 